\title{
INSURREIÇÕES E ESPIRITUALIDADE POLÍTICA NA REVOLUÇÃO ISLÂMICA
}

\author{
Insurrections and political spirituality in the Islamic revolution
}

Gabriela Massarra Santos Heine ${ }^{1}$

\begin{abstract}
RESUMO: A presente proposta de comunicação possui como objetivo abordar as percepções de Michel Foucault ao que ele compreende existir na revolução islâmica noções de insurreição e espiritualidade política. Este trabalho tem como base as observações que foram feitas no conjunto de sua "Reportagem de ideias" escritas pelo filósofo em decorrência as suas duas viagens ao Irã, em 1978 e que ele pôde expor sua visão filosófica sobre aquele momento em que acontecia a revolução Iraniana. Porém, o seu posicionamento foi em diversas situações mal interpretado e algumas críticas ressurgem até hoje como se ele fosse simpático ao regime de aiatolá Khomeini. No livro $O$ enigma da revolta podemos encontrar entrevistas do momento em que o filósofo tentou esclarecer as indagações de seus críticos que por vezes o caracterizava como um intelectual inábil que pactua de uma análise entre filosofia e política. Porém, diferente do que alguns podem pensar, Foucault não analisava a situação do Irã de forma ingênua. Seu interesse era poder compreender de perto a experiência da revolução e perceber quais novas indagações aquele movimento revolucionário trazia à tona ao ocidente.
\end{abstract}

Palavras-chave: Movimento. Insurreição. Espiritualidade.

ABSTRACT: The objective of this communication is to address Michel Foucault's perceptions of what he understands to exist in the Islamic revolution, notions of insurrection and political spirituality. This work is based on the observations that were made in the set of his "Report of ideas" written by the philosopher as a result of his two trips to Iran, in 1978 and that he was able to expose his philosophical vision about that moment when the Iranian revolution happened. However, his position was misunderstood in several situations and some criticisms are still emerging today as if he were sympathetic to Ayatollah Khomeini's regime. In the book O enigma da revolta we can find interviews from the moment when the philosopher tried to clarify the questions of his critics who at times characterized him as an unskilled intellectual who agreed on an analysis between philosophy and politics. However, different from what some may think, Foucault did not naively analyze the situation in Iran. His interest was to be able to understand closely the experience of the revolution and to understand what new questions that revolutionary movement brought to the western.

Keywords: Movement. Insurrection. Spirituality.

\section{NO QUE TANGE AO TRABALHO}

Esta apresentação é resultado da leitura do livro O enigma da revolta (FOUCAULT, 2018). Esse livro leva ao leitor à duas entrevistas de Michel Foucault sobre as manifestações que

\footnotetext{
${ }^{1}$ Graduada em Filosofia pela Universidade Estadual do Ceará - UECE, mestre em Filosofia pela Pontifícia Universidade Católica de São Paulo - PUC SP. E-mail: gabimassarra@hotmail.com
} 
resultaram na revolução islâmica ${ }^{2}$ em 1979. O filósofo prolongou suas observações, no conjunto de sua "Reportagem de ideias" para o Corriere della Sera, em que ele pôde expor sua visão filosófica sobre aquele momento. Porém, o seu posicionamento foi em diversas situações mal interpretado, algumas críticas ressurgem até hoje como se ele fosse simpático ao regime de aiatolá Khomeini ${ }^{3}$ sem reconhecer a gravidade da situação. Também surgiram críticas o caracterizando como um intelectual inábil que pactua de uma análise entre filosofia e política.

Estas entrevistas fazem parte do momento em que o filósofo tentou esclarecer as indagações de seus críticos ${ }^{4}$. Porém, diferente do que alguns podem pensar, Foucault não analisava a situação do Irã $\tilde{a}^{5}$ de forma ingênua. Seu interesse era poder compreender de perto a experiência da revolução. Ele acreditava que o movimento revolucionário iraniano trazia à tona ao ocidente novas indagações como: "O que é uma revolução que não segue uma vanguarda, que não tem um partido ou uma ideologia política? O que é uma revolução sem um programa de governo que projete uma nova sociedade?" (FOUCAULT, 2018, p.9). O seu papel como filósofo, se encontra em compreender esta peculiaridade das lutas, o porquê, como se propaga e como fracassa uma revolta.

Enquanto Foucault analisa o movimento insurrecional como espiritualidade política, ele se torna alvo de muitas críticas, pois seus críticos interpretaram de forma inadequada o que ele queria comunicar com o seu pensamento. Para Foucault, a noção de espiritualidade política nasce de uma leitura que ele fez antes mesmo de observar as manifestações do Irã, cujo referencial teórico estava inspirado em O princípio da esperança em Ernst Bloch. Através desta leitura ele observa surgir uma espiritualidade política parecida com as revoltas camponesas na Europa, o calvinismo e o anabatismo.

O que é Calvino senão a vontade de fazer passar para a política não apenas a crença religiosa, mas toda uma forma de espiritualidade, isto, é, uma relação individual com Deus, com valores espirituais. Pois bem, é o calvinismo, projeto que tem a forma de um outro movimento religioso. Foi o que aconteceu no Ocidente, e foi o que aconteceu neste movimento do ano de 1978 no Irã, creio eu. Pessoalmente [risos], jamais pensei que a espiritualidade política pudesse ser, atualmente, como dizer, uma aspiração... (FOUCAULT, 2018, p.63)

\footnotetext{
${ }^{2}$ Que transformou o Irã em uma república, com o pilar nos princípios religiosos do islamismo.

${ }^{3}$ Ruhollah Musavi Khomeini tinha uma voz bem expressiva como oposição ao regime do Xá. Ele defendia as reformas econômicas, sociais e resgate dos valores religiosos e tradicionais do Irã (Deutsche Welle, 2019).

${ }^{4}$ Foucault retrata na entrevista por Farès Sassine, que a incompreensão de seus críticos foi tão grande que Jornais (tal qual o Le Monde) com seus jornalistas franceses engendraram falsificações de textos, palavras e frases que não eram dele para endossar que o filósofo aprovava as ações dos tribunais islâmicos.

${ }^{5}$ Antes da revolução islâmica, era uma monarquia autocrática pró ocidente (o que suscitava muitas críticas dos opositores), comandada pelo Xá Mohammad Reza Pahlevi.
} 
Ao falar sobre o movimento insurrecional iraniano, o filósofo desenvolve de forma geral a noção de levante, ou seja, pensar nas transformações que as insurreições provocam, quais são as novas formas possíveis de se relacionar com a cultura, com o corpo ou com o trabalho, por exemplo. A espiritualidade a que Foucault refere-se é a de perceber estas novas possibilidades existentes no mundo e para si mesmo.

Quando sugerido em entrevista ao Le Nouvel Observateur para esclarecer o significado da expressão espiritualidade política aos críticos franceses, Foucault responde com uma anedota em que não caberia explicar àquele que procura entender o que está acontecendo com o Irã, mas talvez aos críticos que se incomodam tanto com a expressão, explicar o porquê da sua resistência e irritabilidade. Poderíamos pensar que sua resposta seria algo como: o que uma pessoa diz sobre os outros, diz mais sobre ela mesma. Essa seria como uma proposta de reflexão e talvez autoconhecimento ${ }^{6}$ ? É possível.

Foucault sentia-se estimulado em descobrir qual era a força capaz de enfrentar um regime pavoroso, enquanto o povo não estava munido com armas. Qual seria essa força cabível de uma vontade feroz e obstinada, habilitada em aceitar até mesmo o sacrifício de seus indivíduos? Para o filósofo francês, a resposta não estaria nas ideologias marxista e nem mesmo em uma ideologia revolucionária no sentido ocidental ${ }^{7}$. A crise iraniana à luz de Foucault, era uma reivindicação ao islã, a uma nova forma de vida ligada à religião, que não seria o contraste entre a vida antiga e a vida moderna, mas outra forma de vida. E este movimento de revolta surge decorrente da insatisfação do povo iraniano.

Quando Foucault se refere à espiritualidade, ele não está falando de religião, embora as pessoas misturem os dois, é possível encontrar a espiritualidade na religião como fora dela ${ }^{8}$. A espiritualidade seria a prática que transforma o homem até a renúncia da sua individualidade. $\mathrm{O}$ homem que antes estava sujeito a um poder político, depois de transformado torna-se um sujeito de um saber, de uma experiência ou até mesmo de uma crença. Espiritualidade é a possibilidade de insurgir a si mesmo ao que antes estava fixado, pelo poder político, religioso, por um hábito ou

\footnotetext{
6 "Pode-se imaginar que depois dos grandes...porque afinal, a Europa viveu, isto é, o europeu viveu sob o princípio esperança, que se organizou em torno da ideia de uma revolução política com partidos, um exército, uma vanguarda, o proletariado, etc. Bem, conhecemos a decepção que isso gerou. Assim, poderíamos imaginar que agora, toda forma de revolta, seja ela qual for e seja lá onde ocorrer, desde que não tome essas velhas formas tais como missões, esperança, provoca ao mesmo tempo uma certa irritação e, se preferir, uma espécie de ciúme cultural. Eles não vão fazer uma verdadeira revolução na forma deles, já que nós não conseguimos fazer uma revolução em nossa própria forma." (FOUCAULT, 2018, p.71)

${ }^{7}$ Não caberia a interpretação da situação do Irã com os olhos do ocidente, por isso Foucault faz uma analogia com a espiritualidade política. Foucault questiona o esclarecimento de uma revolta ou revolução do gênero marxista, que para ele reduz as causas das quais "tomaríamos consciência" por uma vanguarda detentora da ciência da sociedade.

${ }^{8}$ Como em religiões sem teologia, nos monoteísmos, no budismo e até mesmo na civilização grega.
} 
uma estrutura social. Esta insurreição proporciona a transformação do sujeito para se tornar o que se é, outro de si.

É certo que as religiões são ao mesmo tempo uma espécie de estrutura de acolhimento para essas formas de espiritualidade, para essas práticas de espiritualidade e limitações. Elas nos prescrevem em que devemos nos tornar outro que si mesmo, em qual direção devemos ir, qual novo estatuto teremos etc. De fato, as religiões constituem uma codificação da espiritualidade. (FOUCAULT, 2018, p. 21)

Foucault acredita que parte das grandes reviravoltas sejam elas sociais, culturais ou políticas encontraram seu espaço na história devido ao seu movimento de espiritualidade. A exemplo do que aconteceu no período entre a idade média e o final do séc. XVI, ocorreram movimentos tão importantes quanto no período revolucionário do séc. XVIII para o séc. XIX.

Houve muitas mudanças nas relações sociais, nas formas de obediência política, nas hierarquias das sociedades. É possível que os historiadores também percebam que a passagem entre os sécs. XV e XVI se fez pelo movimento de espiritualidade que estremeceu as hierarquias religiosas, foi a religião contra ela mesma. Houve os movimentos ascéticos em Flandres, as formas religiosas na Alemanha, o movimento anabatista. Toda propagação de grupos religiosos que insurgiram contra a monarquia inglesa e fizeram acontecer a primeira revolução da história da Europa é percebida por Foucault como espiritualidade. Ela está presente no seio das grandes reviravoltas políticas e culturais, em que a religião pode desempenhar uma função importante de codificadora. É importante apreender os fatos históricos acima através de uma interpretação filosófica, perceber o problema além de sua análise histórica.

\footnotetext{
Essas crises do século XVI foram espirituais...Retomemos o século XIX russo! Será que tudo o que preparou a Revolução de 1917 não foi fundamentalmente um movimento espiritual; será que a grande onda de entusiasmo que produziu esse fenômeno, que em seguida foi retomada pelos bolcheviques, não foi em suas raízes algo profundamente espiritual, no sentido em que o digo, isto é, querer que a situação ou os dados mudem, mas saber que isso não pode mudar se não mudarmos a nós mesmos? Ambos são completamente solidários, e é esse “devir-outro" que está no coração da vontade revolucionária. (FOUCAULT, 2018, p.26)
}

Existe neste devir-outro uma vontade de alteridade em si mesmo, destruir esse outro já conhecido e recriar um outro até então desconhecido, mas necessário que se faça outro, que se transmute, isso é espiritualidade. Rabaut Saint-Étienne é citado no livro para se pensar em uma revolução filosófica, no sentido de recriar uma consciência filosófica nas demais instituições, como uma tábula rasa, destruir para construir em bases mais racionais. Foucault retoma essa ideia sob a ótica que se faça o mesmo com a espiritualidade, sabendo que todo movimento de espiritualidade se utiliza das ferramentas que estão disponíveis no momento. Significa dizer que este movimento 
é real e não do mundo das ideias. O alicerce em que nos encontramos é a ferramenta da nossa transformação. E esta transformação demanda tempo, esforço e prática. É de se pensar que na história do cristianismo, se passaram dois séculos para que surgisse algum tipo de mudança.

Com o tempo, variados grupos sociais têm recusado o estabelecimento de diversas regras de organização social. Sejam porque foram impostas, ou por estarem ultrapassadas, mas certamente por não atenderem aos interesses dos seus membros. E esta rejeição se mostra como um fenômeno social, uma insurreição, em que as pessoas não querem mais ser submetidas ao sujeito da história. Para isso, é preciso agir, praticar a sublevação, recusar a própria identidade, quem somos e se preciso o mundo.

$\mathrm{Na}$ entrevista realizada por Farès Sassine em agosto de 1979, o entrevistador relembra a impressão do filosofo de que existiria naquele momento iraniano, uma vontade geral. $\mathrm{Na}$ contramão, Foucault diz não recordar de sentir essa vontade geral em sua experiência de europeu. Por sempre a perceber de forma delegada ${ }^{9}$. Mesmo nas democracias, como um sistema político em que os cidadãos elegem os seus dirigentes através das eleições essa vontade geral pouco é sentida. Por existir em demasia burocracia, liderança, hierarquia, confisco de poder.

Quando os iranianos se rebelaram, foram para as ruas confrontar o exército, foi uma decisão das pessoas constituintes de um povo. Elas não foram forçadas, não teria um grupo responsável para assumir as consequências, aquela era uma reação de quem não aguentava mais se submeter. Coletivamente, as pessoas não queriam mais aquela condição social, política e religiosa, elas almejavam outra coisa que talvez não fosse um outro regime político, nem um regime de mulás $^{10}$, mas o que elas tinha em suas cabeças, para o filósofo seria algo como uma escatologia religiosa, o suficiente para elas arriscarem a pele quase todos os dias.

Não é a intenção de Foucault dizer que a espiritualidade política é a solução dos problemas do Irã, uma vez que ele recorda os acontecimentos dos séculos XV e XVI. Ele não usou o termo no sentido de ser uma maravilha na terra. Mas como um movimento análogo ao olhar de um ocidental, do que entende por espiritualidade política e que semelhante à espiritualidade de Calvino levou diversos homens às fogueiras.

Farès Sassine supõe na entrevista que o filósofo descreveu o movimento de espiritualidade política no Irã com certa simpatia. Então, Foucault retoma a ideia de quanto é difícil compreendermos algo, de forma adequada, quando ela se mostra hostil. O movimento de insurreição iraniano, ainda que violento, teve um grande peso cultural do país. Os seus pensamentos, hábitos e manifestações sociais são característicos e cabe ao seu povo ter autonomia

\footnotetext{
${ }^{9}$ Existe uma ideia de revolução para o europeu, com uma característica organização de um saber, um sistema político, um mecanismo de partidos, um aparato de ação...

${ }^{10}$ São os clérigos islâmicos. Homem muçulmano, com educação na teologia islâmica.
}

Cadernos Cajuína, V. 6, N. 1, 2021, p. 60-68. 
em buscar as soluções dos seus conflitos. Na visão do filósofo, quando o povo iraniano, opositores da esquerda, liberais e xiitas se juntaram contra o regime do Xá, de opressão, exploração, imperialismo, ele deu início a um processo de insurreição, que é positivo, na medida que o islã permitiu que todos estivessem juntos ativamente. Eles uniram forças para derrubar um regime de pobreza e inflação, de repressão, que censurava, torturava e assassinava seus opositores.

Podemos pensar que o movimento de uma revolução existe pela necessidade de mudança. Porque viver nos ditames daquele momento não é mais suficiente. E a revolução islâmica proporcionou uma profunda mudança na estrutura social do Irã. No começo o processo revolucionário foi guiado pela melhoria das condições de vida do seu povo, talvez com um desejo sob uma perspectiva um pouco mais democrática. O resultado foi a transformação do país em um estado teocrático, governado por um chefe religioso com uma postura extremamente radical, adotando novas leis com base no islamismo. Mas é importante compreender que Foucault comunica exatamente esse movimento de transformação. Porque a mudança não ocorre se permanecermos inertes, apáticos, sem vontade própria. É preciso se fazer movimento, desta forma, com o tempo é possível que vejamos uma renovação significativa a outros olhares distintos.

Toda revolta certamente tem suas razões, mas Foucault se atenta ao cuidado que se deve ter ao tentar reduzir os seus motivos em uma explicação. Segundo ele,

\footnotetext{
Para entender o momento exato em que isso acontece, quando tentamos entender o vivido da revolução, há algo que não pode ser reduzido a uma explicação ou uma razão, por mais miseráveis que sejamos, ou ameaçados de morrer de fome. No momento em que nos revoltamos e dizemos: eu prefiro morrer sob metralhadoras do que morrer de fome, há algo nisso que a ameaça de fome não explica. Existe um jogo entre sacrifício e esperança de que cada um é responsável. Ou então, coletivamente, um povo responsável. Ele mesmo estabelece o grau de esperança e aceitação dos sacrifícios que lhe permitirão enfrentar um exército, uma polícia... (FOUCAULT,2018, p.71).
}

Concordamos com Foucault que a revolução é um acontecimento que se vive e é vivido pelas pessoas. Elas têm consciência do que fazem e que abandonarão parte de sua história. A escolha em arriscar a própria vida é uma decisão, isso não quer dizer que devemos ficar em frente de um fuzil e esperar para morrer. A decisão de morrer ao invés de se submeter, pode ter variadas formas "pode tomar a forma de um comando ou de guerrilhas; pode ser também a forma de um atentado individualista; a forma de um pertencimento a um movimento de massa, de uma manifestação religiosa" (2018, p.75). Essas seriam a expressão da decisão, romper com os seguimentos históricos, a alma da revolução.

A vontade é o que sustenta a revolta, algo que segue além do cálculo de interesses, da imediatidade do desejo. Ela se mostra despida quando alguém diz que prefere a morte. E aqui, esta decisão não é irracional e nem esgotada de desejo. Ela fixa o sujeito em sua própria posição. Ela é 
aquela que diz "eu quero saber", ela é um ato puro do sujeito, "aí acho que nós escapamos do universalismo quando dizemos que finalmente o sujeito nada mais é do que o efeito de um...enfim, daquilo que é determinado por uma vontade" (2018, p.86).

Ter vontade nos permite insurgir. Se quiséssemos mudar algo que achamos intolerável e de repente aparecesse alguém nos propondo uma solução para resolver nossos problemas, impondo uma condição que para isso seria necessário preestabelecer ou fixar algumas exigências depois, isso é ilusório! Porque as pessoas necessitam da vontade como um motor de transformação e não delegar para interesses alheios, para não repetir o que o filósofo diz sentir em sua experiência de europeu, uma vontade delegada.

Existem variadas formas de insurreição. Hoje elas se diferenciam daquelas da idade média, mas elas sempre existirão. Podemos perceber formas de insurreição nos movimentos feministas, negros, LGBTQ+, veganos, contra um tipo de relação familiar, contra uma relação sexual, uma pedagogia, contra um tipo de informação ou pensamento. Sempre é tempo para insurgir e não precisa ser apenas de forma massiva. Ela pode ser diferenciada, analítica quando percebemos que alguns elementos da nossa realidade são induzidos como necessários, naturais e óbvios quando na verdade não são. Porque são condições vendidas, impostas e por isso frágeis, moveis, passivas de sublevação.

\section{CONSIDERAÇÕES FINAIS}

O conjunto de críticas direcionadas a Foucault, nos permite refletir o quanto conseguimos ressurgir de um modelo social, que limita as nossas práticas e pensamentos, que não estimula o autoconhecimento e consequentemente dificulta as nossas relações. É comum encontrarmos pessoas que vivem como promotores e a compreensão do que é dito fica muito difícil. Essas pessoas não conseguem se distanciar da sua ótica de vida para tentar entender o que o outro está querendo dizer. Para isso é preciso se esvaziar, abandonar os seus títulos, suas certezas e ser apenas humano, cuidando de outro.

Quaisquer pessoas, sejam sujeitos simples ou profissionais de uma área, deveriam reconhecer as fragilidades do conhecimento absoluto. Interpretamos que Foucault faz um exercício do pensamento, ao analisar a revolução do Irã "eu jamais tenho certeza do que digo, e adoraria que pudéssemos ter trocas, discussões, e que as pessoas que não estão de acordo pudessem expressar suas discordâncias e fazer perguntas, etc" (2018, p.96). Temos perdido uns aos outros quando não sabemos dialogar, ouvir, compreender ou ao menos tentar. Não precisamos concordar sempre, se pensarmos em autoconhecimento, também não crescemos assim. Mas exercitar a empatia e 
civilidade na comunicação com outra pessoa, buscando compreender o que ela está querendo comunicar.

No final do livro, Christian Laval retoma a ideia foucaultiana de experiência alteradora (aquela em que nos transformamos ou "saímos transformados"), analogamente com a experiência utópica que geralmente não é considerado como um termo de Foucault. Porém a utopia a que ele se refere não é aquela entendida por um ideal futuro, que remete a um conforto, que sabemos que na prática é irreal. Ela se relaciona com a morte, porque requer vontade de transformação e decisão de se deslocar, seria como a espiritualidade, termo que Foucault usa nas suas observações sobre os iranianos.

Segundo Laval (2018), Foucault considera as suas pesquisas uma experiência utópica que tem um objeto (analisa as experiências da história), um objetivo (produzir uma alteração entre o saber e o poder) e um efeito subjetivo (se transformar). Podemos pensar que Foucault tinha a intenção de compartilhar a sua experiência de alteração com o exercício das possibilidades do saber. Visto que a riqueza da filosofia não deveria ser em filosofar para legitimar o que sabemos, mas a sua magnificência se encontra no exercício que o filosofar nos proporciona, que seria perceber formas diferentes de se pensar e viver. 


\section{REFERÊNCIAS}

FARHI NETO, Leon. Governo islâmico e governamentalidade. Revista Lugar Comum, Rio de Janeiro, 2009.

Foucault e a insurreição iraniana. Peri, Florianópolis, v.2, n.2, 2010.

FOUCAULT, Michel. O enigma da revolta. Posfácio de Christian Laval. Editora N-1, junho de 2018.

DEUTSCHE WELLE. Irã os fatos que precederam a Revolução Islâmica. Publicado em 10 fev. 2019. Disponível em: https://www.cartacapital.com.br/mundo/ira-os-fatos-que-precederama-revolucao-islamica/ Acesso em: 10 jun. 2020. 